\title{
EDUCAÇÃO GENERIFICADA: UMA ANÁLISE DO ENSINO TÉCNICO EM ENFERMAGEM EM GOIÁS
}

\author{
Patrícia Fernandes de Oliveira \\ Instituto Tecnológico do Estado de Goiás Sebastião de Siqueira \\ (ITEGO), Goiânia, Goiás, Brasil \\ Aline da Silva Nicolino \\ Faculdade de Educação Física e Dança da Universidade Federal de Goiás \\ (FEFD/UFG-GO), Goiânia, Goiás, Brasil \\ MARIA José do NASCIMENTO \\ Secretaria de Estado da Educação, Cultura e Esporte de Goiás \\ (SEDUCE), Secretaria Municipal da Educação de Goiânia (SME), \\ Goiânia, Goiás, Brasil \\ Paulo César Soares de Oliveira \\ Secretaria de Estado da Educação, Cultura e Esporte de Goiás \\ (SEDUCE), Faculdade Alfredo Nasser (UNIFAN), Goiânia, Goiás, \\ Brasil
}

\begin{abstract}
Resumo: Este estudo descreve as perspectivas de gênero presentes na prática pedagógica de Cursos Técnicos em Enfermagem da cidade de Goiânia/GO, por meio da identificação e análise de saberes que constituem o tema nos documentos regulatórios e nas concepções de estudantes e coordenadores/as. A investigação foi realizada em sete instituições de educação profissional, por meio de pesquisa de campo/exploratória, de abordagem qualitativa, valendo-se de questionário, entrevista e observação participante. As análises mostram que há uma lógica em que o sexo biológico determina o gênero, sobretudo, nos documentos regulatórios do processo de formação, mas que as ideias de multiplicidade das sexualidades, dos gêneros e dos corpos também disputam reconhecimento e resistência, ao serem acionadas na curiosidade, nos questionamentos e nos conflitos.
\end{abstract}

Palavras-chave: Gênero. Técnica/o em Enfermagem. Educação Profissional. Saberes. 


\section{INTRODUÇÃO}

A formação humana integral e o suporte e atenção à saúde são alguns dos princípios legislativos que regem a lógica dos cursos técnicos em Enfermagem, segundo o Conselho Federal de Enfermagem (COFEN). O primeiro princípio visa promover um ensino integral do cuidado humano para atuar nas áreas de promoção da saúde, prevenção de doenças, tratamento e reabilitação do processo saúde-doença do ser humano. Já o segundo, sob um viés mais técnico, exige um saber-fazer dessas competências e habilidades relacionadas à saúde do indivíduo. Ao analisarmos os documentos regulatórios, sobretudo as diretrizes, identificamos que a assistência e o cuidado com o corpo são alguns dos pilares estruturantes do currículo ${ }^{1}$, que recorrem aos saberes biomédicos para fundamentar suas intervenções (BRASIL, 1986).

Compreendemos, então, que tais princípios visam educar o corpo a promover 'hábitos saudáveis', fazendo circular saberes sobre o corpo doente e o corpo sadio. Nesse sentido, é possível dizer que os saberes que constituem a 'verdade' sobre o tema trazem - "modelo anatômico construído pela higiene" (COSTA, 2004, p. 13), para marcar as diferenças sociais no corpo. Sob essa lógica, a sexualidade torna-se um instrumento de regulação e manutenção da ideia de "corpo saudável", em que a heterossexualidade se constitui como norma das relações humanas. Para circular esse discurso, entendemos que os saberes biomédicos são acionados para conformar as diferenças biológicas em desigualdades de gênero, classe, geracional, sexual, étnica.

Esses saberes, ao entrarem em circulação nos projetos pedagógicos, nas disciplinas e nas aulas ministradas nos cursos técnicos em Enfermagem, produzem discussões sobre gênero em meio a disputas, conflitos e resistências. Isto é, aquilo que "escapou" do currículo formal, da lógica anátomo-fisiológica que constitui o corpo, despertou interesses, produziu debates, provocou desordens e possibilitou reflexões. Ao mesmo tempo, observa-se também nas atuais Diretrizes Curriculares Nacionais voltadas para a educação profissional técnica de nível médio (BRASIL, 2012), uma preocupação em incluir temas relacionados à diversidade. O parágrafo XI, da Resolução n6/2012, traz que o "reconhecimento das identidades de gênero e étnico-raciais, assim como dos povos indígenas, quilombolas e populações do campo", são questões a serem discutidas no processo de formação.

Para decifrar as demandas que produziram a necessidade de se discutir questões sobre a diversidade, assim como verificar se foram implementadas no processo de formação, investigamos quais discussões sobre gênero estão presentes na prática pedagógica de cursos técnicos em Enfermagem da cidade de Goiânia/GO, por meio da identificação e da análise de saberes que constituem o tema nas diretrizes que regem a formação, nos planos pedagógicos, nos planos de ensino e nas concepções de estudantes e coordenadores/as. Para levantar essas informações, analisamos os documentos regulatórios, aplicamos questionários às/aos estudantes e entrevistamos as coordenadoras de sete cursos técnicos em Enfermagem da capital goiana. Além disso, foram realizadas observações participante, visando identificar o que se fala sobre o assunto e o que é silenciado. 
Para investigar tais questões é importante trazer a compreensão de gênero com a qual operamos nossas análises, em que a materialização do biológico vai de encontro a essas teorias, por contestarem "a naturalização da diferença sexual" (HARAWAY, 2004, p. 211). Compreensão, portanto, contrária à universalização e a fixidez das bases biológicas, por entender que o conceito engloba as formas de construção social, cultural e linguística que estão implicadas nos processos de diferenciação entre mulheres e homens. O que significa dizer que as instituições, as leis, as políticas, as normas, enfim, os processos simbólicos de cada cultura, ao mesmo tempo em que são constituídos por representações de feminilidade e masculinidade, também produzem essas representações ou mesmo, ressignificam-nas (MEYER, 2008). Estamos considerando, portanto, que esse saber não se constitui isoladamente, mas estabelece relações com outros saberes.

Nesse sentido, parece-nos relevante identificar as ideias, os comportamentos e as práticas realizadas pelas/os estudantes e coordenadoras do ensino profissional em Enfermagem no que se refere à discussão de gênero, no sentido de conhecer e analisar a forma como se dá a produção desses saberes. Isto é, investigar os efeitos dessas disputas que envolvem a discussão de gênero no contexto escolar, permite mostrar quais saberes foram utilizados para produzir alguns discursos sobre o tema. Ao compreendermos discurso como enunciado constituído por vários saberes e, portanto, aquilo que se fala, que se diz, refere-se "ao discurso tal como é" (EDGARDO, 2009, p.120), fazemos o movimento de entender e interrogar "que singular existência é esta que vem à tona no que se diz" (FOUCAULT, 2008, p. 31).

Esse saber, a que se refere, aproxima-se da compreensão descrita por Michel Foucault (2010), que não se limita ao saber da ciência, podendo ou não adquirir status de científico. Entendemos, então, que saberes estão articulados a qualquer prática, comportamento ou acontecimento que represente o domínio de objetos, espaços e conceitos para construir e legitimar uma verdade (FOUCAULT, 2008). O saber a que se faz referência diz respeito às 'verdades' atribuídas ao tema nos contextos educacionais investigados, com base nas descrições das/os estudantes e nas falas das coordenadoras dos cursos técnicos em Enfermagem.

O reconhecimento de saberes e de ações que vem sendo implementados no contexto escolar nos levou a alguns questionamentos: Quais saberes sobre o tema estão presentes nos projetos pedagógicos e nos planos de ensino dos cursos técnicos em Enfermagem? Como a gestão desses cursos compreende o tema? Que estratégias utilizam para tratar o tema na escola? Qual a compreensão das/os estudantes sobre gênero? Tais questões buscam compreender como gênero vem sendo apresentado nos cursos, por quem, como e com qual finalidade. Busca, sobretudo, investigar se há relação deste tema com as questões de prevenção de DST, aids e gravidez na adolescência, como mostram alguns estudos realizados em Goiás, em que as lógicas preventiva e alarmista, justificavam a maior parte dos investimentos dos recursos e das intervenções no contexto escolar em Goiás. (GONÇALVES, 1998; NASCIMENTO, 2013; NICOLINO et al., 2013; NICOLINO; PARAÍSO, 2014).

Com base nisso, apresentamos como argumento que os saberes relacionados ao gênero, presentes nos documentos regulatórios dos cursos são, em sua maioria, constituídos pela lógica heteronormativa ${ }^{2}$, em que o sexo biológico determina quem a 
pessoa deve ser, o que desejar e como se comportar. Ou seja, parte-se da ideia de que homens e mulheres se constituem sob uma materialidade biológica. Observa-se, ainda, que há a circulação de um discurso binário atravessando as falas das/os docentes para constituir os 'corpos saudáveis', sob a justificativa de adequá-los a práticas 'saudáveis e seguras'. Ao mesmo tempo, também é possível identificar uma demanda por parte das/os estudantes e também das coordenadoras em compreender e dialogar sobre o tema sob outras óticas, em que o afeto e o desejo são acionados como estratégias de negociação e resistência.

Diante desse contexto de pouco diálogo, entre as demandas sociais e as novas diretrizes propostas para essa temática no campo educacional, faz-se mister investigar quais as discussões sobre gênero que estão presentes no processo de formação em Técnica/o em Enfermagem, não somente pela escassez dessa discussão no campo da educação profissional, mas também pela necessidade de reflexão, de exercício de cidadania e de respeito aos direitos humanos que a própria dinâmica do trato profissional estabelece com o corpo. Somando-se a tudo isso, tem-se ainda que o trabalho dessas/es profissionais exige habilidades e destrezas afetivas, cognitivas e motoras para observar, valorar, decidir, realizar e interagir com pacientes ${ }^{3}$ e com a equipe de trabalho (BRASIL, 2009). Nesse sentido, espera-se com este estudo produzir conhecimentos sobre o tema no campo da educação profissional em Goiás, evidenciando os modos de ver, sentir e vivenciar as sexualidades e os gêneros que estão em disputa nesse contexto.

\section{METODOLOGIA}

Este estudo valeu-se da pesquisa do tipo exploratória e descritiva, visando familiarizar-se com um assunto ainda pouco conhecido, pouco explorado (GIL, 2008). Para realizar a pesquisa de campo, buscou-se incluir instituições públicas e privadas, assim como garantir que todas as regiões da grande Goiânia fossem contempladas. Após esse mapeamento, foram selecionadas sete instituições de Educação Profissional de Goiânia/GO, que oferecem o Curso Técnico em Enfermagem, localizadas em diferentes setores da cidade (sul, leste central e central), classificadas da seguinte forma: uma escola pública estadual, uma escola conveniada à rede pública do estado e cinco escolas privadas ${ }^{4}$. A escolha também levou em consideração o tempo da instituição, de modo a inserir as instituições consideradas tradicionais na amostra deste estudo. Ao todo, $54 \%$ do total de instituições que oferecem o Curso Técnico em Enfermagem, no ano de 2014, fez parte desta pesquisa.

Para realizar a coleta dos dados, recorremos aos documentos regulatórios da área (leis e resoluções), aos projetos pedagógicos e planos de ensino dos sete cursos de Técnico em Enfermagem. Entende-se que a análise documental é um importante instrumento utilizado na abordagem qualitativa, por possibilitar melhor compreensão e ampliação das informações obtidas das/os participantes com a pesquisa de campo (FREITAS, 2013). Assim, após análise desses materiais, sistematizamos as informações mais representativas sobre as questões que envolvem as discussões de gênero em categorias, selecionando as ideias e as mensagens de maior circulação sobre o tema. Essas análises possibilitaram elaborar um questionário que foi entregue as/aos estudantes do último 
ano do curso técnico em Enfermagem, assim como desenvolver um roteiro de entrevista semiestruturado que foi aplicado às coordenadoras dos sete cursos investigados.

O questionário aplicado às/aos estudantes buscava mapear as seguintes informações: os saberes que elas/es apresentam sobre gênero, se há disciplinas que trabalham o tema, as mediações pedagógicas e o posicionamento sobre a discussão de gênero na formação inicial de professoras/es. Já a entrevista realizada com as coordenadoras visava identificar: de que forma as questões de gênero são percebidas no cotidiano de cada curso, se há a discussão da temática nas mediações pedagógicas das/os docentes e conhecer o posicionamento das coordenadoras sobre o tema no processo de formação docente.

Considerando o objetivo proposto, optamos pela realização de uma pesquisa de campo, por meio de uma abordagem qualitativa, inspirado na análise de conteúdo, sistematizada por Laurence Bardin (1977). O método possibilitou organizar as ideias por temas afins, permitindo a construção de categorias de análises sobre os saberes de gênero apresentados por estudantes, coordenadoras e documentos regulatórios (Leis, projetos pedagógicos e planos de ensino) dos cursos técnicos em Enfermagem de Goiânia.

\section{CURRÍCULO GENERIFICADO: ANÁLISE DOS DOCUMENTOS REGULATÓRIOS E DA CONCEPÇÃO DE ESTUDANTES E COORDENADORES/AS DOS CURSOS TÉCNICOS EM ENFERMAGEM}

Ao lermos os documentos disponibilizados pelas sete instituições pesquisadas, verificamos que os objetivos apresentados nos projetos pedagógicos e nos planos de ensino recorrem a legislação para definir os princípios norteadores da formação da/o Técnica/o em Enfermagem. Ao descrevê-los, evidenciam o suporte $e$ a atenção à saúde com ênfase à formação e a atuação profissional, voltado ao processo saúde-doença, seguindo as determinações do COFEN. Assim como, trazem a formação humana integral, pautando-se na compreensão das relações sociais e no respeito à diversidade do sujeito, como previsto na Resolução $n^{\circ}$ 6/2012. Esses dois princípios estão presentes em todos os projetos pedagógicos dos cursos analisados, sendo os maiores norteadores do processo de formação da área. Ambos são citados várias vezes nesses documentos, como pode ser visto nos objetivos propostos de duas instituições:

\footnotetext{
Formar técnicos em enfermagem [...] sedimentados em um pensar integral do cuidado humano para atuar nas áreas de promoção da saúde, prevenção de doenças, no tratamento e reabilitação no processo saúde-doença do ser humano/família/comunidade (Instituição X5).

Preparar profissionais para atuar em ações de promoção, prevenção, recuperação e reabilitação na saúde dos indivíduos comprometidos com o pensar integral do cuidado humano (Instituição X4).
}

De um modo geral, os projetos pedagógicos dos cursos trabalham com a ideia de saúde acoplada à formação humana integral. Isto é, trabalham com a ideia de integralidade para superar o pragmatismo e instituir cientificidade ao processo de cuidado. Buscam, sobretudo, desconstruir a lógica dicotômica de trabalho manual e intelectual, que marca a história da profissão, como mostra estudiosas/os da área: 
Trata-se de superar a redução da preparação para o trabalho ao seu aspecto operacional, simplificado, escoimado dos conhecimentos que estão na sua gênese científico-metodológica e na sua apropriação histórico-social. [...] Formação que, neste sentido, supõe a compreensão das relações sociais subjacentes a todos os fenômenos (FRIGOTTO; CIAVATTA; RAMOS, 2005, p. 85).

Nesse sentido, observa-se nos objetivos dos projetos pedagógicos e nas ementas das disciplinas, um discurso de superação das lógicas pragmática e mecanicista, buscando instituir cientificidade ao processo de cuidar. Ao olharmos para os planos de ensino, identifica-se diversos objetivos voltados para o "despertar da sensibilidade" e da "promoção da ética" (Instituições X4 e X5), estabelecendo como compromisso da profissão o "reconhecimento e a promoção da organização social com vistas à resolução de problemas relativos à saúde" (Instituições X2 e X3). Ou seja, é possível identificar esforços por parte das instituições em mostrar que as intervenções estão fundamentadas em conhecimentos científicos e que a prática profissional vem acompanhada da teoria. Assim como, esforços para mostrar o quanto a profissão exige o "reconhecimento dos direitos do cidadão" (Instituições X6, X7 e X1), para "desenvolver os princípios da assistência ao paciente sem discriminação de qualquer espécie" (Instituição X1).

O que significa dizer que as exigências previstas na legislação estão formalizadas nos documentos que regem os cursos de formação em Técnica/o em Enfermagem na cidade de Goiânia, sobretudo nas dimensões social e cultural referentes à ética e aos direitos do cidadão. Diante da formalização de valorização dessas dimensões, buscamos investigar se nesses documentos há menções sobre as questões que envolvem a discussão de gênero, por entendermos, como Dagmar Meyer (2005, p.11), que gênero é "uma ferramenta conceitual, política e pedagógica central [...] para se problematizar algumas formas de organização sociais vigentes e as desigualdades delas decorrentes".

Sob essa perspectiva, identificamos duas lógicas presentes nas propostas curriculares dos cursos que constituem o discurso sobre gênero. A primeira, refere-se ao campo da saúde, guiada pela lógica biologicista, em que há uma exigência do saber-fazer de competências e de habilidades relacionadas à promoção, prevenção e recuperação da saúde. Os saberes que a constituem envolvem os diversos aspectos relacionados ao processo patológico, procedimento cirúrgico, procedimento curativo, tratamentos clínicos, procedimento farmacológico, os quais tratam de conhecimentos e técnicas básicas no exercício da profissão, conferindo pouca visibilidade às questões social, histórica e política que também constituem as pessoas. As disciplinas que trabalham com essa proposta são: Anatomia e Fisiologia Humana, Fundamentos da Enfermagem, Microbiologia e Parasitologia, Tratamento Clínico, Assistência a Pacientes em Clínica Médica e Cirúrgica, Farmacologia, Biossegurança e Segurança no Trabalho, Primeiros Socorros, Técnicas Básicas em Enfermagem, Nutrição.

A segunda lógica traz a ideia de formação humana integral articulada com as dimensões social, histórica e cultural. Para isso, busca conectar a discussão do corpo como meio ambiente, com as questões relacionadas à ética e aos direitos humanos. Sob essa perspectiva, foi possível identificar um conjunto de disciplinas que se propõe a discutir gênero, ao trabalhar com princípios humanos e de cidadania para tratar as relações humanas. É preciso lembrar que a Resolução nº 6/2012 (BRASIL, 2012) sinaliza a discussão 
de gênero como um princípio norteador da educação profissional, o que reforça essa demanda na organização curricular e pedagógica dos cursos técnicos. Compreendemos, com isso, que há um esforço por parte das instituições em reconhecer como científicos esses saberes, por meio da inserção de termos indicados na legislação e da proposição de ações que atendam a demandas sociais. O reconhecimento desses saberes, descritos nos documentos regulatórios, leva-nos a pensar que essa compressão pode estar relacionada com "as muitas formas sociais e culturais que, de forma interdependente e interrelacionada, educam homens e mulheres como sujeitos de gênero" (MEYER; SOARES, 2004, p.15), como observado nos objetivos de algumas disciplinas:

Disciplina Programa do Adolescente - Aplicar os princípios e fundamentos humanísticos, éticos e de cidadania no convívio com as pessoas e no desempenho de suas atividades profissionais (Instituição X2); Disciplina Ética e Psicologia Aplicada à Saúde - Relacionar-se profissionalmente de modo ético, responsável, eficaz e humanizado (Instituição X5); Disciplina Saúde da Mulher - Promover a organização social reconhecendo os direitos do cidadão (Instituição X7).

Essas disciplinas, de modo geral, trabalham com as ideias de relações interpessoais, ética e cidadania, dentro dos campos epistemológicos da Psicologia do Desenvolvimento, da Sociologia das Representações Sociais e da Fisiologia da Saúde. Ao analisar cada uma delas, verificamos que quatro instituições (X1, X2, X4 e X6) mencionaram o termo gênero em seus planos de ensino. Uma delas é a instituição X1, que traz no conteúdo da disciplina "Psicologia Aplicada à Saúde", o título Sexualidade e Gênero. Ao investigarmos as competências e as habilidades dessa disciplina, verificamos que os objetivos e os conteúdos abrangem as relações pessoais e interpessoais, o que pode ser observado nas referências bibliográficas que tratam de temas relacionados à ética profissional e às relações humanas no trabalho ${ }^{5}$. Apesar de gênero aparecer como um conteúdo a ser ministrado, não há qualquer menção sobre o tema em todo o documento.

Já nas instituições $\mathrm{X} 2$, X4 e X6 foi possível identificar a temática, tanto para tratar das identidades de gênero e de sexualidade, quanto para tratar das doenças sexualmente transmissíveis (DST). No que se refere às identidades, é possível observar no título de uma obra Trabalho, saúde e gênero na era da globalização (OLIVEIRA, 1977), da instituição X2, uma referência que articula classe e gênero à discussão de saúde. As instituições X4 e X6 trazem duas fontes teóricas intituladas Guia da sexualidade (GEOVANINI, 2010) e Gênero, sexualidade e saúde: um olhar da enfermagem (WALDOW, 2006), em que recorrem ao campo da saúde para fazer a leitura sobre gênero e sexualidade. Tal compreensão parte da análise dessas referências ${ }^{6}$, ao verificarmos que elas trabalham com as questões voltadas à diferença, à sexualidade e ao gênero, nas dimensões social e cultural, para fazer conexões com a saúde fisiológica e ao trabalho da/o enfermeira/o. Observamos, ainda, que as ideias apresentadas nessas referências valem-se de uma discussão sobre gênero e sexualidade pautada em saberes do campo da saúde, em que a prescrição de uma determinada sexualidade heterossexual constitui o gênero feminino e o masculino.

No que tange às referências voltadas para as doenças sexualmente transmissíveis ${ }^{7}$, identificamos que elas exploram temas como AIDS, prevenção, métodos contraceptivos e sexo, como pode ser visto nos títulos das fontes teóricas utilizadas pelas instituições X2, X4 e X6: "Aprendendo sobre aids e doenças sexualmente transmissíveis" 
(BRASIL, 2001); "Manual de Controle das doenças sexualmente transmissíveis" (BRASIL, 2005); "Aids e doenças sexualmente transmissíveis" (ROCHA, 2000). As análises desses textos mostram que os conhecimentos apresentados centram na questão fisiológica do organismo, prevalecendo as prescrições sobre prevenção e medicalização dos corpos.

Confrontando essas análises com as respostas descritas pelas/os estudantes nos questionários, ao serem questionadas/os sobre quais disciplinas trabalham as questões de gênero, responderam: Anatomia, Obstetrícia/Ginecologia, Promoção e Prevenção da Saúde, Saúde do Idoso e Materno Infantil. A disciplina de "Anatomia" foi a mais citada pelas/os estudantes de todos os cursos investigados, apesar de não trazer a discussão sobre gênero em seus objetivos, nos conteúdos e nas referências bibliográficas. No plano de ensino foi possível verificar a discussão sobre o corpo humano e seus respectivos sistemas fisiológicos, incluindo o sistema reprodutor masculino e feminino. Sob a mesma lógica, em que prevalece os saberes biomédicos, a disciplina de "Obstetrícia/Ginecologia", a segunda mais mencionada pelas/os estudantes, trazem em seus conteúdos o ciclo reprodutivo, as doenças sexualmente transmissíveis, os tipos de parto e a questão da sexualidade. Como descrito pelas estudantes:

Já foi abordado em Anatomia e um pouco em Obstetrícia. O professor explicou as diferenças morfológicas do sexo masculino e feminino e assim passamos a compreender melhor porque alguns homens e mulheres agem de formas diferentes. (Natália, Instituição X7). Na disciplina Promoção e Prevenção foi trabalhado principalmente sobre a transmissão de doenças sexualmente transmissíveis diferenciando a anatomia masculina e feminina (Ana Lúcia, Instituição X5).

Ao ler o plano de ensino dessas disciplinas, observamos que Anatomia, Obstetrícia/Ginecologia, Promoção e Prevenção da Saúde, Materno Infantil e Saúde do Idoso, em ordem decrescente de citações, trabalham com as fases do desenvolvimento humano (infância, adolescência, adulta, velhice), e com saberes biológicos para explicar o sistema reprodutor masculino e feminino. Segundo as/os estudantes, gênero e sexualidade são tratados sob essa lógica, em que características biológicas de homens e mulheres são apresentadas como expressões das diferenças que constituem os corpos masculinos e femininos.

Já foi abordado em Anatomia e um pouco em Obstetrícia. O professor explicou as diferenças morfológicas do sexo masculino e feminino e assim passamos a compreender melhor porque alguns homens e mulheres agem de formas diferentes (Natália, Instituição X7).

$\mathrm{Na}$ disciplina Promoção e Prevenção foi trabalhado principalmente sobre a transmissão de doenças sexualmente transmissíveis diferenciando a anatomia masculina e feminina (Ana Lúcia, Instituição X5).

Nas disciplinas, Materno Infantil e Promoção e Prevenção, foi abordado sobre a sexualidade, sobre as prevenções de doenças e a gravidez indesejada. (Antônio, Instituição X4), assim como da importância de respeitar a opção sexual de cada pessoa (Beatriz, Instituição X6).

Em Saúde do Idoso falamos dos perigos das doenças sexualmente transmissíveis e da falta de diálogo entre os parceiros (Priscilla, Instituição X5). 
Assim, é possível identificar nas respostas das/os estudantes e nos documentos que regem o curso técnico em Enfermagem que há uma preocupação em promover uma educação corporal voltada à profilaxia, à prevenção, à promoção de saúde e ao cuidado. Para isso, os conhecimentos anátomo-fisiológicos são muito acionados para dar 'respostas' sobre comportamentos e modos de ser das pessoas. Essas formas constituem representações corporais de um feminino e de um masculino centrado no sexo, para constituir as representações sobre desejo, amor, saúde, identidade. $O$ que significa dizer que os valores morais de uma determinada época e sociedade, assim como os saberes que conquistaram maior prestígio científico dentre outros saberes populares locais, constituem parte da representação do que seja saudável, doente, belo, feminino, masculino. Isto é, o corpo está representado e entrecruzado pelos marcadores geração, religião, classe, sexualidade, gênero, raça/etnia, escolaridade, localidade. $O$ ato de educar, portanto, não é neutro!

Nesse sentido, a transmissão de técnicas básicas do campo da Enfermagem é um exemplo de que a técnica pressupõe expressões corporais que extrapolam a lógica biologicista, como segue nas falas das professoras:

[...] quando a gente começa as técnicas básicas, que é o conteúdo básico da Enfermagem, a gente vai entrar na intimidade do paciente, vai dar banho, fazer a higiene íntima. Essas coisas muito íntimas do paciente, por isso eu acho que é preciso ter algo que esclareça aos alunos os tipos de sexualidades, os tipos de gêneros e também falar sobre o respeito e a ética [...] a importância de respeitar a sexualidade de cada um, para minimizar os preconceitos (Coordenadora, Instituição $\mathrm{X} 3$ ).

Acho que, justamente, por conta dessa particularidade de cuidar do corpo do outro, né? A privacidade do paciente que vai ser invadida, eles (os/as alunos) têm muito receio ao lidar sobre esses assuntos (gênero e sexualidade). Por isso, acho importante esses temas, pois eles não fazem parte da grade curricular (Coordenadora, Instituição X2).

Com relação a outras disciplinas citadas pelas/os estudantes, como: Ética, Saúde da Mulher, Programa do Adolescente, Saúde Coletivae Psicologia, é preciso dizer que elas não entraram nesta análise, pela inexpressiva quantidade de menções e por não trazerem de forma explicita termos e temas sobre gênero. Ao mesmo tempo, também verificamos um considerável número de estudantes que deixaram a pergunta em branco e outras/os que descreveram não haver disciplina que trate sobre o tema no processo de formação. Em outra pergunta, sobre como identificam a discussão de gênero no processo de formação, a maior parte das/os estudantes considera importante que o tema esteja presente no curso técnico em Enfermagem, por acreditar que as questões sobre o tema estão presentes no contexto escolar, sobretudo em ações de preconceito e de discriminação, ressaltando que ainda há pouca informação sobre o assunto, como segue:

"É importante falar sobre esse assunto no curso, pois temos muitas dúvidas sobre gênero e sexualidade". Assim como, "precisamos estar mais orientados para lidar com todos os tipos de diferenças, classe, gênero, sexo" (Lúcia e Kelly, Instituição X1). "É preciso deixar de lado preconceitos, velhos pensamentos errados" (Marcos, Instituição X1), para isso é importante, segundo o estudante Luiz, da Instituição X7, que tais temas sejam trabalhados no currículo, "pois a todo tempo conviveremos 
com todos os tipos de classe, sexo e gênero [...] assim, temos que conhecer mais a fundo sobre essas questões”. E, ainda, como descreve José, instituição X4: “Esse tema é importante porque lidaremos com o ser humano nas suas diversidades, tanto na questão sexual, de gênero, cultural, religiosa. Por isso, precisamos conhecer mais." ${ }^{\prime 8}$

As descrições feitas pelas/os estudantes de diferentes instituições, mostram por um lado que há uma demanda sendo produzida no contexto escolar sobre o tema e, por outro, que os saberes anátomo-fisiológicos não estão sendo suficientes para dar conta das questões que envolvem as discussões sobre gênero e sexualidade. Trata-se de identificar que há um limite teórico que esbarra nas fronteiras de gênero, como explica Guacira Lopes Louro (2008, p. 17), ao escrever que "o gênero e a sexualidade guardam a inconstância de tudo o que é histórico e cultural: por isso, às vezes escapam e deslizam". O que significa dizer, que para uma determinada norma se materializar nos corpos é preciso ser reiterada e, nesse sentido, "a matriz heterossexual ao delimitar os padrões a serem seguidos, fornece, ao mesmo tempo, a pauta para as transgressões" (LOURO, 2008, p. 17).

É possível dizer, ainda, que há uma invisibilidade de alguns saberes socioculturais, como o desejo e o afeto, no processo de formação, e que essa suposta ausência identificada nos documentos regulatórios se reflete nas demandas feitas pelas/os estudantes e coordenadoras por uma formação humana integral. Ou seja, para além do que há sistematizado no currículo formal como uma formação integradora do ser humano, há fortes indícios de que as/os estudantes querem compreender os modos pelos quais as relações social, política, cultural e, portanto, de poder constituem as pessoas. Compreender, sobretudo, como se dá os processos de nomeação, classificação e hierarquização das expressões corporais, em que as diferenças fisiológicas, transformamse em desigualdades sociais.

Observa-se, nesse sentido, que o currículo está dando conta de trazer saberes que fundamentam as diferenças biológicas entre homens e mulheres, como muitas/os citaram, mas, ao mesmo tempo, não conseguimos identificar nos documentos, nas descrições das/os estudantes e nas falas das coordenadoras, o que nessas diferenças podem integralizar a/o humana/o. Compreendemos, nesse sentido, que o currículo cumpre com o papel de formar profissionais para atuar na lógica que constitui o homem e a mulher como sujeitos diferentes biologicamente, mas não na lógica de dar visibilidade às desigualdades que essas diferenças produzem. Como descreve uma estudante "a gente aprende a entender melhor as pessoas de outra sexualidade [homossexual]" (Rosa, Instituição X3), mas não problematiza como a heterossexualidade se constitui como norma ou porque há uma "outra" sexualidade que precisa ser compreendida, vista como "desviante". Essas questões aparecem na escrita de um estudante ao perguntar "Porque alguns homens se identificam como mulheres quando meninos ou crianças?" (Augusto, Instituição X7).

Percebe-se, portanto, o interesse das/os estudantes em conhecer saberes que possibilitem outras reflexões e explicações para além do determinismo biológico. Apesar da pergunta partir de uma lógica essencialista, em que o sexo biológico é o determinante dos desejos, dos afetos e das representações sociais, a questão traz, sobretudo, os limites que esse pensamento biologicista produz sobre uma lógica subordinada à generificação 
de ser feminina ou ser masculino. Há um pensamento binário sendo operacionalizado para pensar os corpos, em que gênero se apresenta como masculino ou como feminino. Essa lógica dá as diretrizes e também os limites para se pensar os sujeitos (SCOTT,1995).

\section{ALGUMAS CONSIDERAÇÕES PARA FINALIZAR!}

As análises mostram, de um modo geral, que há uma lógica em que o sexo biológico determina o gênero, sobretudo nos documentos regulatórios que regem o processo de formação, mas que as ideias de multiplicidade das sexualidades, dos gêneros e dos corpos também disputam reconhecimento, ao serem reveladas na curiosidade, nos questionamentos e no desconforto produzido por estudantes e coordenadoras no contexto escolar. É sobre essa multiplicidade e, sobretudo, sobre esse "desconforto" em lidar com os temas que gostaríamos de chamar a atenção. Para analisar mais atentamente a questão da multiplicidade, recorremos à entrevista da coordenadora da instituição X3: "Penso que é importante esclarecer para os alunos a questão dos preconceitos com os outros gêneros, né? Como ocaso da homossexualidade". Observa-se em sua fala uma separação entre homo e hetero, em que o "outro" gênero é marcado por sua identidade sexual, em que a homossexualidade torna-se o desvio da norma heterossexual.

A fala anuncia que há uma lógica normativa que posiciona a heterossexualidade como sendo a sexualidade estável e natural. Ao mesmo tempo, essa mesma lógica também produz a/o "outro", dando visibilidade e materializando outras formas de afeto e desejo entre as pessoas. $O$ que significa dizer que a dispersão e a difusão dessas representações muitas vezes gera um 'desconforto', que vamos nomeá-lo de provocativo, pois desestabiliza referenciais teóricos essencialistas e, ao mesmo tempo, também possibilita (des)construções, como pode ser visto na entrevista de uma coordenadora da instituição X6, ao relatar as ações realizadas para dar suporte a uma formação humana integral: "[...] uma vez eu trabalhei ética com os alunos e falei a seguinte frase pra eles: vocês têm que estar preparados para não chocar sua paciente, ao perguntar o nome dela e ela falar João, né! Então...essa questão de estar aceitando as diferenças".

Ao justificar a importância de uma educação humana integral no curso técnico em Enfermagem, a coordenadora reforça que há uma "regularidade" sendo operacionalizada no processo de formação, em que a nomeação da pessoa se alinha ao sexo-gênero-sexualidade, em uma relação mimética do gênero com a materialidade do corpo (LOURO, 2009, p. 90). Assim, o "choque" poderia ser lido tanto pela "falta de alinhamento" da representação de feminilidade e de masculinidade, quanto pela transgressão que o desalinhamento provocou nos modos de vivenciar seus gêneros e suas sexualidades. $E$, nesse sentido, encerramos este texto.

Compreendemos, como Debora Britzman, que a invisibilidade de alguns saberes, assim como a ignorância, "é um efeito e não uma ausência de conhecimento" (BRITZMAN, 1996, p. 91), e ao incorporar o discurso de que é preciso "aceitar as diferenças" é possível identificar que há lógica heterossexual conduzindo o currículo formal e as falas das/os estudantes e coordenadoras. O que significa dizer, que há um processo de pedagogização dos corpos sendo produzido na reiteração, mas também nos conflitos e nas negociações. Isto é, as análises mostram que há uma lógica em que o sexo biológico determina o gênero, sobretudo nos documentos regulatórios do processo de formação, mas que as ideias de multiplicidade das sexualidades, dos gêneros e dos corpos também disputam 
reconhecimento e resistência ao serem acionadas na curiosidade, nos questionamentos e no desconforto produzido no contexto escolar.

Artigo recebido em: 24/08/2017

Aprovado para publicação em: 08/12/2017

\section{GENERALIZED EDUCATION: AN ANALYSIS OF TECHNICAL EDUCATION IN NURSING IN GOIÁS}

ABSTRACT: This study investigates which discussions on gender are present in the pedagogical practice of Nursing Technical Courses in Goiânia / GO, through the mapping of knowledge that constitute the subject in the regulatory documents and in the conceptions of students and coordinators. The study was carried out in seven institutions of professional education, through field / exploratory research of qualitative approach, using the questionnaire, interview and participant observation. The analyzes show that there is a logic in which biological sex determines gender, especially in the regulatory documents of the formation process, but that the ideas of multiplicity of sexualities, genders and bodies also dispute recognition and resistance, when they are activated by curiosity, questioning and conflicts.

KEYWORDS: Gender. Nursing Technical. Professional education. Knowledge.

\section{EDUCACIÓN GENEREFICADA: ANALISIS DE LA ENSEÑANZA TÉCNICA EM FERMERÍA EN GOIÁS}

RESUMEN: Este estúdio describe sobre las perspectivas de género presentes em La práctica pedagógica de Cursos Técnicos em Enfermería de la ciudad de Goiânia/GO, por medio de la identificación y análisis de saberes que constituyen el tema en los documentos regulatorios y en las concepciones de estudiantes y coordinadores/as. La investigación se realizó en siete instituciones de educación profesional, por medio de investigación de campo/exploratória, de enfoque cualitativo, valiéndose del cuestionario, entrevista y observación participante. Las análisis muestran que hay una lógica en que el sexo biológico determina el género, aún mas, en los documentos regulatórios del proceso de formación, pero que las ideas de multiplicidad de las sexualidades, de los géneros y de los cuerpos también disputan reconocimiento y resistencia, al ser accionadas en la curiosidad, en los cuestionamientos y en los conflictos.

PALABRAS CLAVE: Técnica/o em Enfermería. Educación Profesional. Saberes.

\section{NOTAS}

1) O termo traz a ideia de conteúdos científicos que foram selecionados e sistematizados para constituírem o currículo oficial do curso. Esses conhecimentos representam, portanto, as expectativas dos documentos regulatórios do campo de atuação. 
OLIVEIRA, P. F.; NICOLINO, A. S.; NASCIMENTO, M. J.; OLIVEIRA, P. C. S.

2) Heteronormatividade é compreendida como a produção e a reiteração compulsória da norma heterossexual, em que se supõe que todas as pessoas sejam (ou devam ser) heterossexuais, seguindo o alinhamento sexo-gênero-sexualidade (LOURO, 2009, p. 90). Esse conceito estabelece uma relação mimética do gênero com a materialidade do corpo, em que se atribui ter um pênis a ser obrigatoriamente másculo (COLLING; NOGUEIRA, 2014). Portanto, a heteronormatividade está "fundada no modelo heterossexual, familiar e reprodutivo. Ela se impõe por meio de violências simbólicas e físicas dirigidas principalmente a quem rompe as normas de gênero" (MISKOLCl, 2012, p. 46-47).

3) O termo paciente refere-se ao indivíduo que está sob algum tratamento de saúde. Esse termo ao contrário de "doente" ou "enfermo", pressupõe a relação do indivíduo com um especialista ou uma instituição de saúde (SAITO, 2013).

4) As sete instituições foram denominadas de $X 1, X 2 \ldots$, assim como as sete coordenadoras entrevistadas de cada instituição pertencente. As/os estudantes foram nomeadas/os com nomes fictícios, seguindo a identificação descrita no questionário. As identificações (estudantes, coordenadoras e instituições) seguiram as normas éticas de sigilo, estipuladas e combinadas previamente no Termo de Consentimento Livre e Esclarecido, protocolo n 11859613.9.0000.5083 disponível no endereço eletrônico:http://www.saude.gov.br/plataformabrasil.

5) BOFF, Leonardo. Saber Cuidar - ética do humano - compaixão pela terra. 11a Ed. Petrópolis: Vozes: 2004.; WALDOW, Vera R. Cuidar - Expressão Humanizadora da Enfermagem. Santos: Vozes, 2006.

6) GEOVANINI, Telma. Gênero, Sexualidade e Saúde: um olhar da enfermagem. Arujá/SP: Giracor, 2010.; OLIVEIRA, Eleonora Menicucci. Trabalho, Saúde e Gênero na Era da Globalização. Goiânia: AB Editora, 1977.; ROVERATTI, Dagmar. Guia da Sexualidade. São Paulo: Ferrari, 2007.

7) BRASIL.Aprendendo sobre aids e doenças sexualmente transmissíveis: Livro da família/Ministério da Saúde, Coordenação Nacional de DST e Aids. Brasília: Ministério da Saúde, 2001. BRASIL. Manual de Controle das doenças sexualmente transmissíveis. Ministério da Saúde, Secretaria de Vigilância em Saúde, Programa Nacional de DST e Aids. Brasília: Ministério da Saúde, 2005. ROCHA, Néviton Oliveira. Aids e doenças sexualmente transmissíveis. São Paulo: Geração Saúde, 2000.

8) As aspas foram utilizadas nesta citação para melhor visualização das diferentes descrições feitas pelas/os estudantes.

\section{REFERÊNCIAS}

BARDIN, L. Análise de conteúdo. Lisboa: Edições 70, 1977.

BOFF, L. Saber Cuidar - ética do humano - compaixão pela terra. $11^{\text {a }}$ Ed. Petrópolis: Vozes, 2004.

BRASIL. Lei no 7.498, de 25 de junho de 1986. Dispõe sobre a regulamentação do exercício da Enfermagem, e dá outras providências. Diário Oficial da União. Brasília. Disponível em: <http://www.planalto.gov.br/ccivil_03/leis/l7498.htm > Acesso em 28 abr. 2014. 
BRASIL. Aprendendo sobre aids e doenças sexualmente transmissíveis: Livro da família/Ministério da Saúde, Coordenação Nacional de DST e Aids. Brasília: Ministério da Saúde, 2001.

BRASIL. Manual de Controle das doenças sexualmente transmissíveis. Ministério da Saúde, Secretaria de Vigilância em Saúde, Programa Nacional de DST e Aids. Brasília: Ministério da Saúde, 2005.

BRASIL. Gênero e Diversidade na Escola: formação de professoras/es em gênero, sexualidade, orientação sexual e relações étnico-raciais. Ministério da Educação. Belo Horizonte: UFMG, 2009.

BRASIL. Parecer CNE/CEB 16/99.Trata das Diretrizes Curriculares Nacionais para Educação Profissional de Nível Técnico. Disponível em:

$<$ http://portal.mec.gov.br/setec/arquivos/pdf_legislacao/tecnico/legisla_tecnico_parece r1699.pdf> Acesso em: 7 fev. 2014.

BRASIL. Resolução CNE/CEB 6/2012. Define as Diretrizes Curriculares Nacionais para a Educação Profissional de Nível Médio. Disponível em: Diário Oficial da União, Brasília, seção1, p.22, 2012.

$<$ http://portal.mec.gov.br/index.php?option=com_docman\&view=download\&alias=116 63-rceb006-12-pdf\&category_slug=setembro-2012-pdf\&ltemid=30192> Acesso em: 3 mar. 2014.

BRITZMAN, D. O que é essa coisa chamada amor - identidade homossexual, educação e currículo. Trad. Tomaz Tadeu Silva. Educação e Realidade, v 21, n 1, jan./jun., 1996.

COSTA, J.F. Ordem médica e norma familiar. 5ed. Rio de Janeiro: Edições Graal, 2004.

EDGARDO, C. Vocabulário de Foucault-Um percurso pelos seus temas, conceitos e autores. Trad. Ingrid Müller Xavier. Belo Horizonte: Autêntica editora, 2009.

FOUCAULT, M. Vigiar e Punir. Petrópolis: Vozes, 2006.

FOUCAULT, M. A arqueologia do saber. 7. ed. Trad. Luiz Felipe Baeta Neves. Rio de Janeiro: Forense Universitária, 2007.

FOUCAULT, M. História da Sexualidade l: a vontade de saber. Rio de Janeiro: Edições Graal, 2010.

FREITAS, J. D. A. Aula de Língua Portuguesa, gênero e raça na Educação Técnica integrada ao Ensino Médio: diálogos e deslocamentos. 2013. 251f. Tese (Doutorado em Letras e Linguística). Programa de Pós-Graduação em Letras e Linguística. Universidade Federal de Goiás, Goiânia, GO, 2013. 
OLIVEIRA, P. F.; NICOLINO, A. S.; NASCIMENTO, M. J.; OLIVEIRA, P. C. S.

FRIGOTTO, G.; CIAVATTA, M.; RAMOS, M. (Orgs.). Ensino Médio Integrado: concepções e contradições. São Paulo: Cortez, 2005.

GIL, A. C. Como elaborar projetos de pesquisa. São Paulo: Atlas, 2008.

GONÇALVES, E. Educação sexual em contexto escolar. da formação de professores/as à sala de aula. 1998. 188 f. Dissertação (Mestrado em Educação) - Faculdade de Educação da Universidade Federal de Goiás, Goiânia, GO, 1998.

HARAWAY, D. “Gênero" para um dicionário marxista: a política sexual de uma palavra. Campinas/SP: Cadernos Pagu, n 22, p. 201-246, 2004.

LOURO, G. L. Um corpo estranho: ensaios sobre sexualidade e teoria queer. Belo Horizonte/MG: Autêntica, 2008.

LOURO, G. L. Heteronormatividade e homofobia. In: JUNQUEIRA, R. D. (Org). Diversidade sexual na educação. Brasília: MEC, UNESCO, 2009, p. 85-93.

MEYER, D. E. E. Gênero e educação: teoria e política. In: LOURO, G. L.; FELIPE, J.; GOELLNER, S. (Orgs). Corpo, gênero e sexualidade: um debate contemporâneo na educação. Petrópolis: Vozes, 2005.

; SOARES, R. Corpo Gênero e Sexualidade nas práticas escolares: um início de reflexão. In: MEYER, D. E. E.; SOARES, R. (Orgs.). Corpo Gênero e Sexualidade. Porto Alegre: Mediação, 2004.

Gênero, Sexualidade e Currículo: In: Educação para

a igualdade de gênero. Salto para o futuro: Ano XVIII, Boletim 26, nov., 2008.

NASCIMENTO, M. J. do. Formação docente e educação sexual: (re)memórias das propostas da rede municipal de ensino de Goiânia/GO (1990 a 2000). 2013. 103f. Dissertação (Mestrado em Educação) - Programa de Pós-Graduação em Educação da Pontifícia Universidade Católica de Goiás, Goiânia, GO, 2013.

NICOLINO, A. et al. Educação sexual e políticas públicas: limites e possibilidades das secretarias. In: NICOLINO, A.; LEITE, J. de O.; WANDERLEY, L. (orgs.). Educação Sexual em Goiás. Goiânia: Editora PUC, 2013.

NICOLINO, A.; PARAÍSO, M. A. Escolarização da sexualidade: o que mostram as dissertações e teses de Goiás. Curitiba, Educar em Revista (Dossiê gênero, sexualidade e educação: feminismos, pós-estruturalismo e teoria quer). Edição Especial, n. 1, Editora UFPR, p. 171-193, 2014.

OLIVEIRA, E. M. Trabalho, Saúde e Gênero na Era da Globalização. Goiânia: AB Editora, 1977. 
ROCHA, N. O. Aids e doenças sexualmente transmissíveis. São Paulo: Geração Saúde, 2000.

SCOTT, J. Gênero: uma categoria útil de análise histórica. Educação \& Realidade. Porto Alegre, v. 2, n. 20, p.71-99, Jul./Dez., 1995.

WALDOW, V. R. Cuidar - Expressão Humanizadora da Enfermagem. Santos: Vozes, 2006.

Patrícia Fernandes de Oliveira: Coordenadora de Integração Escola-comunidade do Instituto Tecnológico do Estado de Goiás Sebastião de Siqueira - Itego. Formada em Educação Física pela Universidade Federal de Uberlândia (UFU) e Mestre em Direitos Humanos pela UFG. Professora de Educação Física da Rede Pública de Goiás.

E-mail: professorapatricia25@gmail.com

Aline dA Silva Nicolino: Formada em Educação Física pela Universidade Estadual Paulista (UNESP/Rio Claro) e Pós-Doutora em Educação pela Universidade Federal de Minas Gerais (UFMG).

E-mail: aline.nicolino@gmail.com

MARIA JosÉ DO NASCIMENTO: Formada em Pedagogia, com habilitação em Administração Escolar e Orientação Educacional, pela Pontificia Universidade Católica de Goiás (PUC/GO).

E-mail:nmariaj@gmail.com

Paulo César SoARes de Oliveira: Formado em História pela UFG e mestre em Educação pela UFG/GO

E-mail: libras.paulo@hotmail.com 